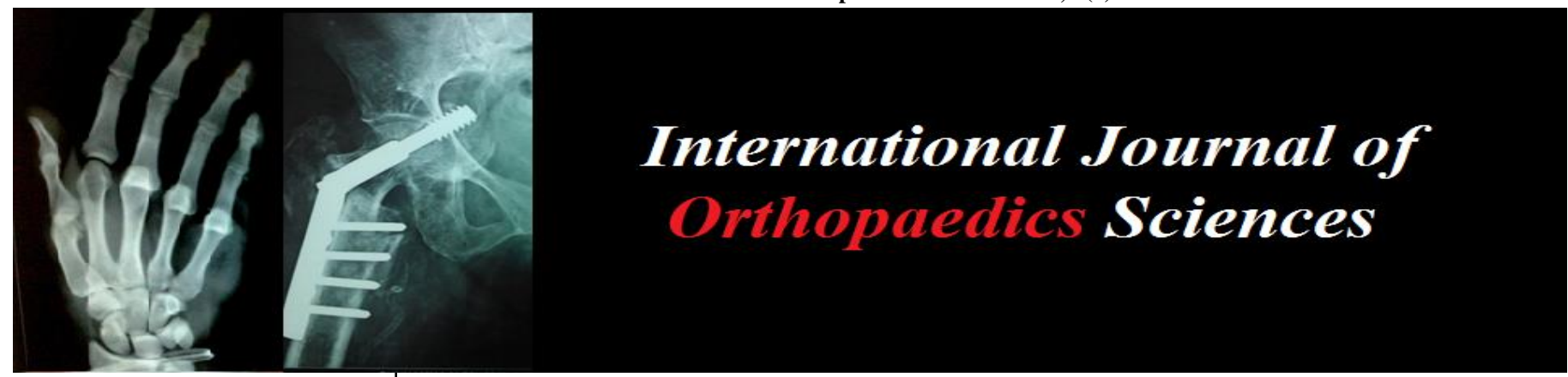

ISSN: $2395-1958$

IJOS 2018; 4(4): 858-865

(C) 2018 IJOS

www.orthopaper.com

Received: 01-08-2018

Accepted: 05-09-2018

Abhishek

Department of Orthopaedics, Sanjay Gandhi institute of trauma and Orthopaedics, Bangalore, Karnataka, India

\section{Shekar M}

Department of Orthopaedics, Sanjay Gandhi institute of trauma and Orthopaedics,

Bangalore, Karnataka, India

\section{Prakashappa TH}

Department of Orthopaedics, Sanjay Gandhi institute of trauma and Orthopaedics,

Bangalore, Karnataka, India
Correspondence

Abhishek

Department of Orthopaedics,

Sanjay Gandhi institute of

trauma and Orthopaedics,

Bangalore, Karnataka, India

\section{Functional outcome following treatment of distal tibia fractures using locking compression plate}

\author{
Abhishek, Shekar M and Prakashappa TH
}

DOI: https://doi.org/10.22271/ortho.2018.v4.i41.111

\section{Abstract}

Aims and Objectives

To Study functional outcome, efficacy and safety of distal tibia fracture by locking compression plate fixation.

Methods: This was a prospective study consists of 25 consecutive cases of distal end tibia both intrarticular and extraarticular fracture selected after applying inclusion and exclusion criteria operated with LCP fixation at Sanjay Gandhi institute of trauma and Orthopaedics from June 2015 to June 2017. Functional outcome was assessed using American orthopedic foot and ankle society score (AOFAS) and visual analogue scale (VAS) at 3, 6 and 12 months postoperatively.

Results: At 12 months, the mean AOFAS was 84.24. Five patients (20\%) had score more then 90 (excellent), 11(44\%) had score between 81-90 (good), 8(32\%) had score between 71-80(fair) and 1(4\%) had score less then 70 (poor).

Mean AOFAS score improved from 71.36 (at 3 month) to 79.96 (at 6 month) and 84.24 (at 1 year).

Mean VAS score at the end of 1 year followup was 22.4.VAS score was calculated after activity of daily life (i.e. walking on level ground) $18(72 \%)$ patients had mild pain. $4(16 \%)$ had no pain and $3(12 \%)$ had moderate pain after activity. No patient had severe pain.

$17(68 \%)$ cases in the study had fracture union without any complications. $8(32 \%)$ cases had postoperative complications ranging from superficial wound infection to delayed union and secondary arthrosis.

Conclusion: Distal tibia fractures are challenging injuries not only because ankle joint has very low thresh hold for anatomic and bio mechanical aberrations but also due to huge importance of soft tissue in its healing. A constant balance has to be maintained to get antomical reduction with minimal soft tissue handling. In a closed fracture of distal end tibia, low profile LCP using MIPPO technique is currently best option for such a fracture.

Keywords: distal tibia fracture LCP fixation, intrarticular distal tibia LCP fixation

\section{Introduction}

Distal tibial fractures are not rare these days and account for fewer than $10 \%$ of all lowerextremity fracture. These fractures are more common in males than in females ${ }^{[1,2]}$. The average patient age is 35 to 40 years. These injuries most commonly result from motor vehicle accidents or falls from height ${ }^{[2]}$.

The severity of these injuries, complexities and the limitations of various treatment methods, have been well described in the literature, but excellent medium and long-term results of treatment continue to elude the patients sustaining these fractures.

Open reduction plate fixation has been used since 1960s with variable results. In current scenario precontoured locking compression plate (LCP) with low profile seems like a formidable treatment options but complexity involved with this fracture in the form of highly complex fracture morphology, relative susceptibility of soft tissue envelope for necrosis on manipulation, and finally very low thresh hold of ankle joint for mechanical axis deviation in case of malunion.

Forty-three percent of previously working individuals remained unemployed at the time of follow-up and $68 \%$ of those patients attributed their inability to work to the sequelae of their tibial plafond fracture as per many studies ${ }^{[3-6]}$.

Important questions such as to what degree does an articular surface need to be reduced, how 
can one accurately assess the amount of displacement after reduction and internal fixation, and how to account for difficult-to measure biologic differences between individuals with seemingly similar injuries remain unanswered. Even though accurate surgical reconstruction with minimization of iatrogenic complications should remain the goal in the treatment of these fractures, certain socioeconomic factors well outside of the surgeon's control appear to have substantial influence on patient outcomes after these injuries.

In our study we have tried to find answers to some of the questions under the heading of functional outcome of closed distal end tibia fractures fixation using locking compression plate.

Over the last 35 years the approch for treatment of distal end tibia fracture has changed substantially owing to advent of CT scan which allowed better understanding of fracture morphology.Simultaneously has evolved is understanding of surrounding soft tissue, and its management while trying to realign the fracture fragments as anatomical as possible.

Although many treatment approaches and protocols have been evolved over the time but there is no single optimal treatment protocol exists for these challanging injuries. Also, long-term outcome data from randomized comparative treatment trials is lacking.However, most of the studies done on distal tibia fracture management suggests that the surgeon must try to balance fracture reduction and stability, specially that of the articular surface, with minimal possible soft tissue descection. Despite optimal treatment of AO/ OTA C-type tibial plafond fractures with anatomical articular reconstruction, restoration of distal tibial alignment, and avoidance of surgical complications, the outcome is not always favorable. The irreversible injury that occurs to the chondral surface and other supporting structures continues to be delineated and likely represents important variables in patient's outcomes ${ }^{[7-}$ 11]

\section{Materials and Methods}

Our study was a prospective observational study consists of 25 consecutive cases of distal end tibia fracture selected after applying inclusion and exclusion operated with LCP fixation at Sanjay Gandhi institute of trauma and Orthopaedics from June 2015 to June 2017

\section{Inclusion criteria:}

1. Adults of (18-65) years

2. Patients with closed intrarticular and extraarticular distal end tibia fractures.

Patients with other ipsilateral fractures, fracture with head injury, pathological fractures and old ankle fractures were excluded from the study.

All the cases were evaluated with preoperative $\mathrm{x}$ rays and $\mathrm{CT}$ scan (Pictures $1-4$ ).

After prior informed consent, a pre-operative anesthetic evaluation and pre-op planning of fixation were made.

Under anesthesia, subjects were put in supine position on a standard operating table. Open reduction and internal fixation (ORIF) or closed reduction with minimal invasive percutaneous plate osteosynthesis (MIPPO) with locking compression plate done under $\mathrm{c}$ arm guidance. Incision and approach decided by soft tissue injury and fracture pattern. In all the cases of associated fibula fracture fixation was done using open reduction/closed reduction with plate, $\mathrm{k}$ wires or screws. Tibia fixation was always followed by fibula fixation.
Intraoperatively reduction of highly communited fractures was done using temporary ankle spanning fixator. In some cases cancellous autograft was used to fill the gap in periarticular-metaphyseal region created after elevation of articular fragments.

Post-operatively depending upon strength of fixation in few patients below knee slab was applied, mobilized without weight bearing on $5^{\text {th }}$ to $7^{\text {th }}$ day, full weight bearing started depending on the fracture configuration, callus response and associated injuries.

Assessment was done at OPD following postoperative visits at 1,2,3,6 months and at 1 year. At follow-up visit, patients were evaluated clinically (pain score, soft tissue status) and radiologically (alignment, fracture reduction and union) and also complications were noted. The final outcome was assessed according to visual analogue score (VAS) and American orthopedic foot and ankle society score (AOFAS).

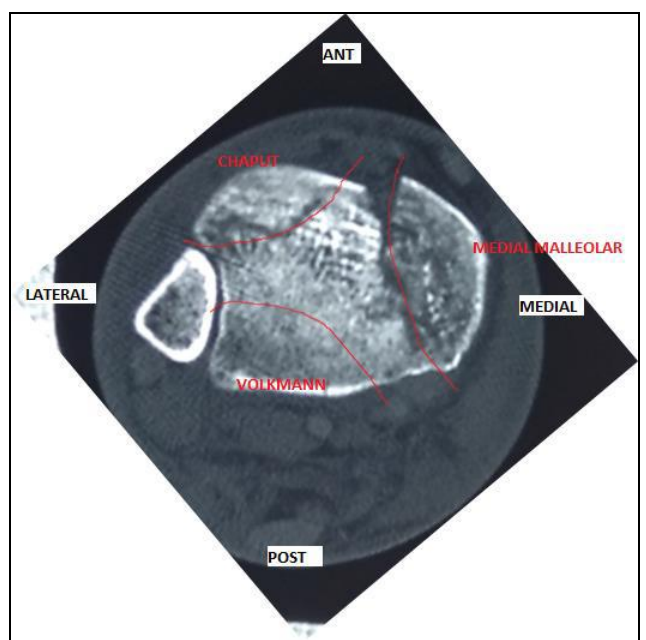

Picture 1: Transverse section through plafond showing three main fragments of distal tibia.

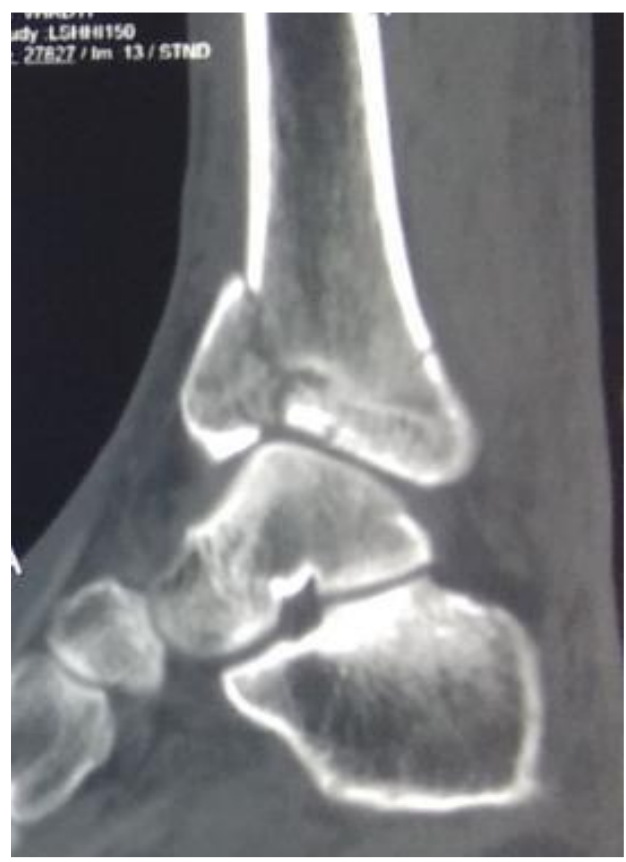

Fig 2: CT scan saggital cut showing anterosuperior displacement of talus against tibial plafond. (Note the central and anterior communition typical of axillary force) 


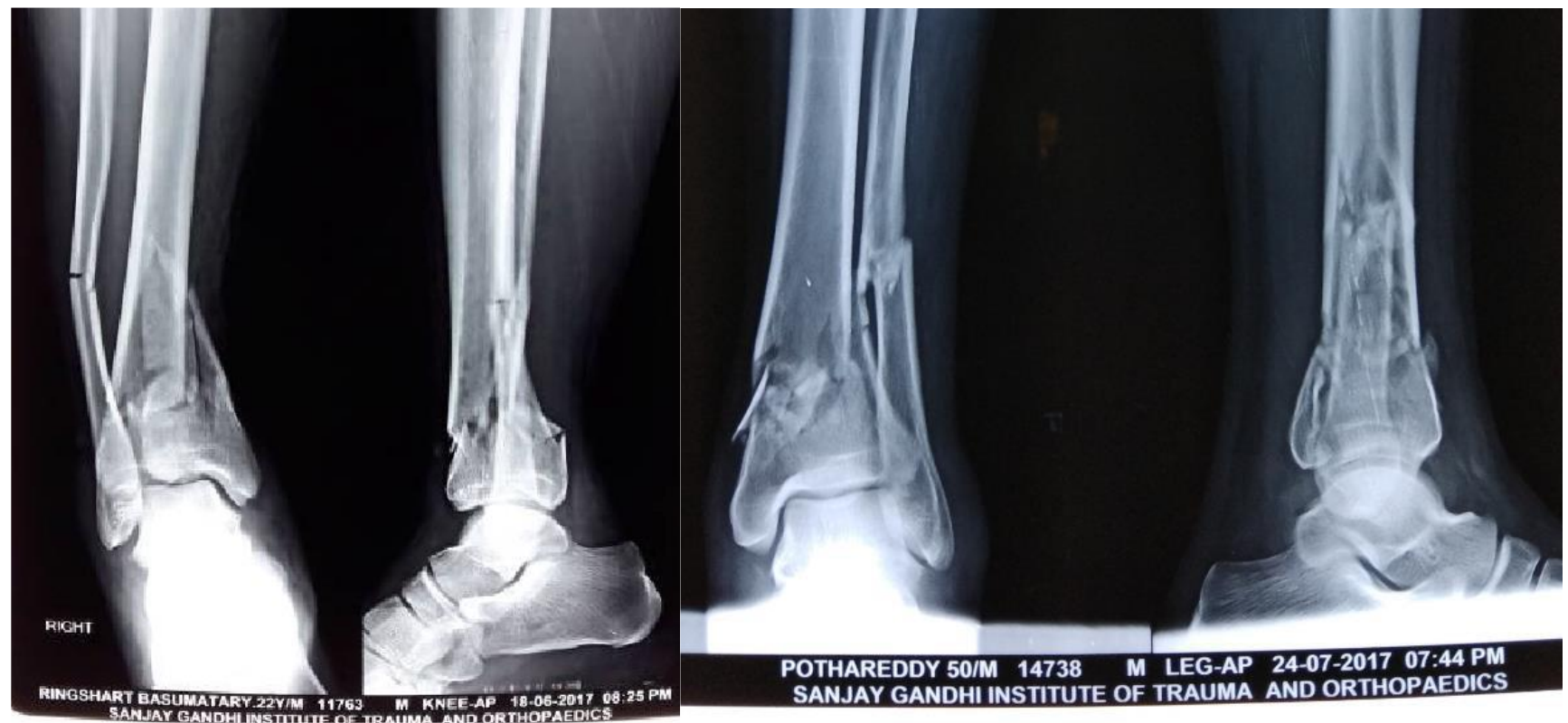

Picture 3: A. Tension fibular failure is commonly identified with tibial plafond fractures that present with varus angulation B. Compressive fibular failure is commonly seen with tibial plafond fractures that present with valgus angulation.

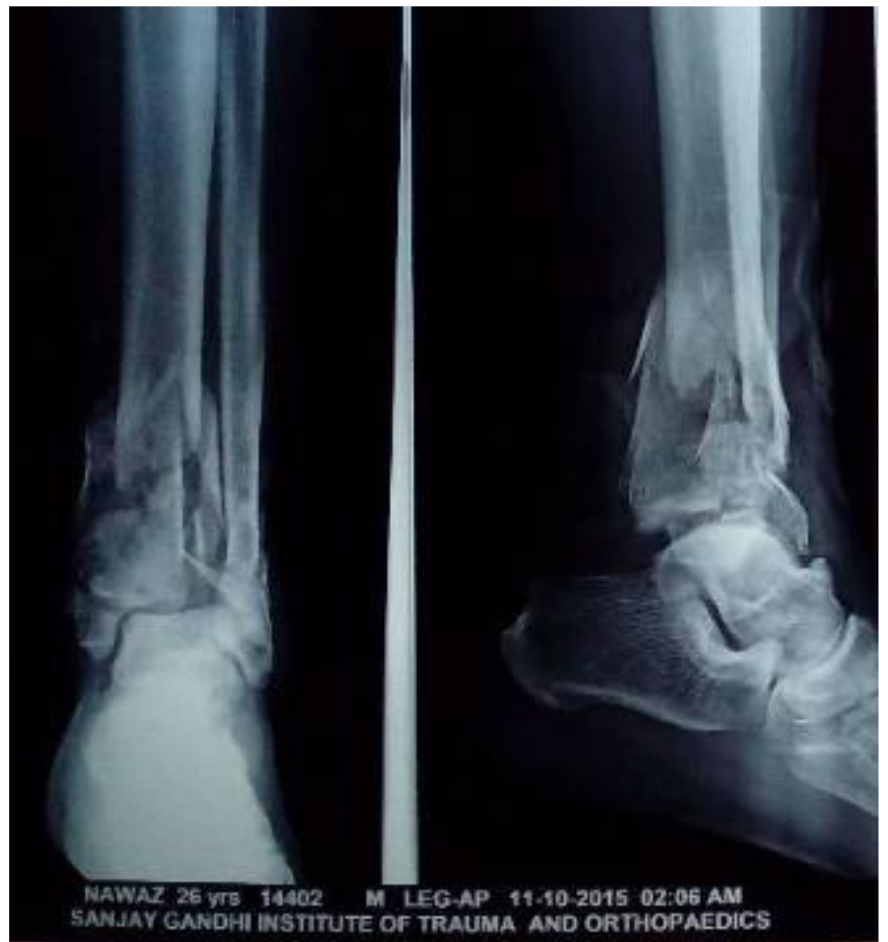

Picture 4: AO 43C3 C type fractue with communitted fibula fracture

\section{Results}

Mean age of the patients was 38.25 years (SD \pm 6.39$)$, ranging from 18 years to 65 years. 14 cases involved the right tibia and 11 involved left side. Out of 25 cases there were 21(84\%) male patients and $4(16 \%)$ female patients. The most common mode of injury was RTA for $18(72 \%)$ cases, $4(16 \%)$ cases had history of fall from height and $3(12 \%)$ had self-fall.

In our study $\mathrm{AO}$ type 43C1 (complete intrarticular without communition) was the most common fracture presentation 7 cases $(28 \%)$ followed by 5 cases $(20 \%)$ of type $43 \mathrm{C} 2$ fractures. There were 4 cases $(16 \%)$ of type 43B 1 and 4 cases (16\%) of 43B2, 3 cases (12\%) of type 43A3 fracture and one case in each type 43A1,B3, and 43C3 group.

10 cases were operated using MIPPO technique rest 15 cases were operated using open technique. Average surgical procedure timing was 80.59 minutes (range 45-124 minutes) in our study. Patients were followed up for a mean of 14 months (range 12-16 month). The mean time from injury to surgery was 5.28 days (range, 1-12) days. The mean hospital stay was 11.88 days (range, 4-18) days. The mean time for complete radiological union was 15.28 weeks (range 12-23). The mean time to full weight bearing was 17 weeks (range, 13-23) weeks.

3 fractures went for delayed union. No secondary procedure was required and all three fractures united eventually.

Mean ankle dorsiflexion at 1 year followup was 11.2 degrees (range 5-15).Mean planter flexion was 33.12 degrees (range 20-42). At 12 months, the mean AOFAS was 84.24.5 patient (20\%) had score more then 90 (excellent), 11(44\%) had score between 81-90 (good), 8(32\%) had score between 71-80(fair) and $1(4 \%)$ had score less than 70 (poor).

Mean AOFAS score improved from 71.36 (at 3 month) to 79.96 (at 6 month) and 84.24 (at 1 year). Mean VAS score at the end of 1 year followup was 22.4.VAS score was calculated after activity of daily life (i.e. walking on level ground) $18(72 \%)$ of the patient had mild pain.4(16\%) had no pain and $3(12 \%)$ had moderate pain after activity. No patient had severe pain.

17 cases in the study had fracture union without any complications.

Superficial wound complication infections were reported in $3(12 \%)$ cases. One patient had post-operative blebs another two had superficial infection which responded to culture specific intravenous antibiotics and daily non adhesive dressing.

There was one incidence of deep surgical site infection resulted in exposure of implant after $8^{\text {th }}$ post-operative day which was treated with local flap cover and 3 weeks of culture sensitive antibiotics. This patient had grade C4A (pigmentation, eczema) and initially in presence of swelling it was masked. Patient was also a known diabetic with poor prior control of blood sugars.

One patient developed discharging sinuses from lateral scar site and diagnosed with fibula osteomyelitis. Patient was a known chronic smoker and alcoholic and continued intake during the treatment duration. Implant removal with sinus 
excision and sequestrecomy and saucerization was done after union was completed. Healing took place without any further complication

Two patients had persistent ankle pain. One of them had post traumatic arthritis treated with NSAIDS, and physiotherapy. Second patient had a fall and suffered injury to anterior inferior tibiofibular ligament and was treated conservatively with ankle immobilization and NSAIDS.

Four patients had coronal plane deformity (distal tibia malunion) which was not clinically significant.

\section{Discussion}

In our study the mean age of the patients was 38.25 years (SD \pm 6.39 ), ranging from 18 years to 65 years is consistant with current litrature.

Table 1: Mean age of the patient sustaining distal tibia fracture

\begin{tabular}{|c|c|}
\hline Study & Mean age (in years) \\
\hline${\text { Vidovic D } \text { et al. }{ }^{[12]}}^{[13]}$ & 40.1 \\
\hline Duckworth AD et al. $^{[13]}$ & 42 \\
\hline Our study & 38.25 \\
\hline
\end{tabular}

The mode of injury was RTA for 18 (72\%) cases and 4(16\%) cases had history fall from height and $3(12 \%)$ had self fall. Almost all the current litrature on pilon fracture points to high velocity road traffic accident as the most commen mode of injury.

The VAS after union of fracture at 1 year on the scale is consistant with study by sunmez MM et al. and Chen DW et $a l$., in our study VAS was calculated just after patient had a walk for about hundred meters.

Table 2: VAS score following fixation using LCP

\begin{tabular}{|c|c|}
\hline Study & VAS score \\
\hline Sonmez MM et al. $^{[14]}$ & $2.58 \mathrm{~cm}$ \\
\hline Chen DW et al. $^{[15]}$ & $1.4 \mathrm{~cm}$ \\
\hline Our study & $2.24 \mathrm{~cm}$ \\
\hline
\end{tabular}

AOFAS in our study is consistant with multiple studies. Final score was calculated after complete union at minimum 12 month of followup.

Table 3: AOFAS score at minimum 12 month of followup

\begin{tabular}{|c|c|}
\hline Study & AOFAS score \\
\hline Sonmez MM et al..$^{[14]}$ & $87.50 \pm 4.05$ \\
\hline Chen DW et al. ${ }^{[15]}$ & 87.8 \\
\hline${\text { Bhat R } \text { et al. }{ }^{116]}}$ al. $^{[13]}$ & 83.6 \\
\hline${\text { Duckworth AD } \text { et }^{[17]}}^{\text {Hong J } \text { et al. }}{ }^{[1]}$ & 76.2 \\
\hline Our study & 87.3 \\
\hline
\end{tabular}

\section{Complications}

Superficial wound complication is the most commen post operative complication in LCP fixation as pointed out by multiple studies. To comment accurately on secondary arthritis long term followup is required. All of our complication incidences were comparable to the current litrature.

Table 4: Complications following distal tibia LCP fixation

\begin{tabular}{|c|c|c|c|c|c|c|c|}
\hline Study & $\begin{array}{c}\text { Sup.wound } \\
\text { complication }\end{array}$ & $\begin{array}{c}\text { Deep wound } \\
\text { complications }\end{array}$ & osteomylitis & $\begin{array}{c}\text { Delayed } \\
\text { union }\end{array}$ & $\begin{array}{c}\text { Non } \\
\text { union }\end{array}$ & $\begin{array}{c}\text { Secondary } \\
\text { arthritis }\end{array}$ & stiffness \\
\hline Duckworth AD et al. ${ }^{[13]}$ & $8 \%$ & $8 \%$ & - & - & - & - & - \\
\hline Carbonel Escobar et al. ${ }^{[18]}$ & $13 \%$ & - & - & - & $10 \%$ & $13 \%$ & - \\
\hline $\begin{array}{c}\text { Howard JL et al. }{ }^{[19]} \\
\text { Sirkin M et al. }{ }^{[20]}\end{array}$ & $5-17 \%$ & - & - & - & - & - & - \\
\hline $\begin{array}{c}\text { Bacon S et al. }{ }^{[21]} \\
\text { Grose A et al. }{ }^{[22]} \\
\text { Leonard M et al. }{ }^{[23]} \\
\text { Patterson MJ et al. }{ }^{[24]} \\
\text { Sirkin M et al. }{ }^{[20]}\end{array}$ & - & - & - & - & - & $0-16 \%$ & - \\
\hline Bourne RB et al. ${ }^{[25]}$ & - & - & - & - & - & $5-26 \%$ & - \\
\hline Our study & $12 \%$ & $4 \%$ & $4 \%$ & $8 \%$ & $0 \%$ & $4 \%$ & $0 \%$ \\
\hline
\end{tabular}

Although ideal operative treatment modality has yet to be found, unstable and displaced extra-articular distal tibial fractures can be treated with numerous methods including external fixation, ${ }^{[26,27]}$ open or percutaneous reduction and plate fixation, ${ }^{[28,29]}$ medullary nailing, ${ }^{[30,31]}$ and combinations thereof. The fracture pattern and status of the local soft tissue envelope are the major determinants for the surgical technique chosen.

Open wounds may or may not be extended as a component of the surgical approach. Frequently, the soft tissues are the most traumatized over the distal tibia and avoidance of incisions in this region is always advised. One of the most important factors in choosing the appropriate surgical approach for a given injury is the location of the fracture lines and the associated comminution. The most frequently used approaches for articular injuries are the anterolateral and the anteromedial.

Many authors have established that closed management of displaced intra-articular distal tibial plafond fractures strongly suggests that the tibiotalar joint poorly tolerates articular incongruity and talar subluxation ${ }^{[32-34]}$. Most of displaced distal tibial fractures are managed operatively; particularly those with displaced intra-articular fracture fragments. According to Thomas et al. (utilized CT-based image analysis to quantify acute pilon injury characteristics) ${ }^{[35]}$ a visible incongruity at the tibial plafond that is demonstrated on plain radiographs should be considered an indication for operative reduction and fixation in properly selected patients. Associated angular malalignment and/or talar subluxation further compromise tibiotalar joint function, and are strong indications for operative management

\section{Conclusion}

1. Primary LCP fixation of closed distal tibia fracture is an effective method for stable fracture fixation providing thorough study of soft tissue envelope, fracture morphology and medical comorbidities has been done prior to fixation.

2. Early ankle mobilization is possible as LCP allows stable fixation especially in communited and relatively poor 
quality of bone.

3. In Associated fibula fracture antomical reduction is desired as it provides indirect reduction of plafond which in turn allows less soft tissue dissection and percutaneous fixation of fracture.

4. In highly communited fracture especially associated with communited fibula fracture intraoperative ankle spanning fixator provides satisfactory reduction.

5. Whenever possible MIPPO is preffered. No touch technique of dissection is advised for reduction and fixation. In case of open reduction dissection and exposure should elivation of full thickness flaps at fracture site.

6. Chronic smoking, chronic alcoholic consumption, poor diabetic control and older age are the major factors compromising local soft tissue healing.

7. Most common post-operative complication is superficial wound necrosis. Overall functional outcome at the end of one year followup was satisfactory in majority of patients. Long term follow-up is required to accurately determine incidence of post traumatic arthritis.

Distal tibia fractures are challenging injuries not only because ankle joint has very low threshhold for anatomic and biomechanical abrerrations but also due to huge importance of soft tissue in it's healing. A constant balance has to be maintained to get antomical reduction with minimal soft tissue handling. In a closed distal tibia fracture, low profile LCP using MIPPO technique is currently best option for such a fracture.

\section{Illustrative Cases}
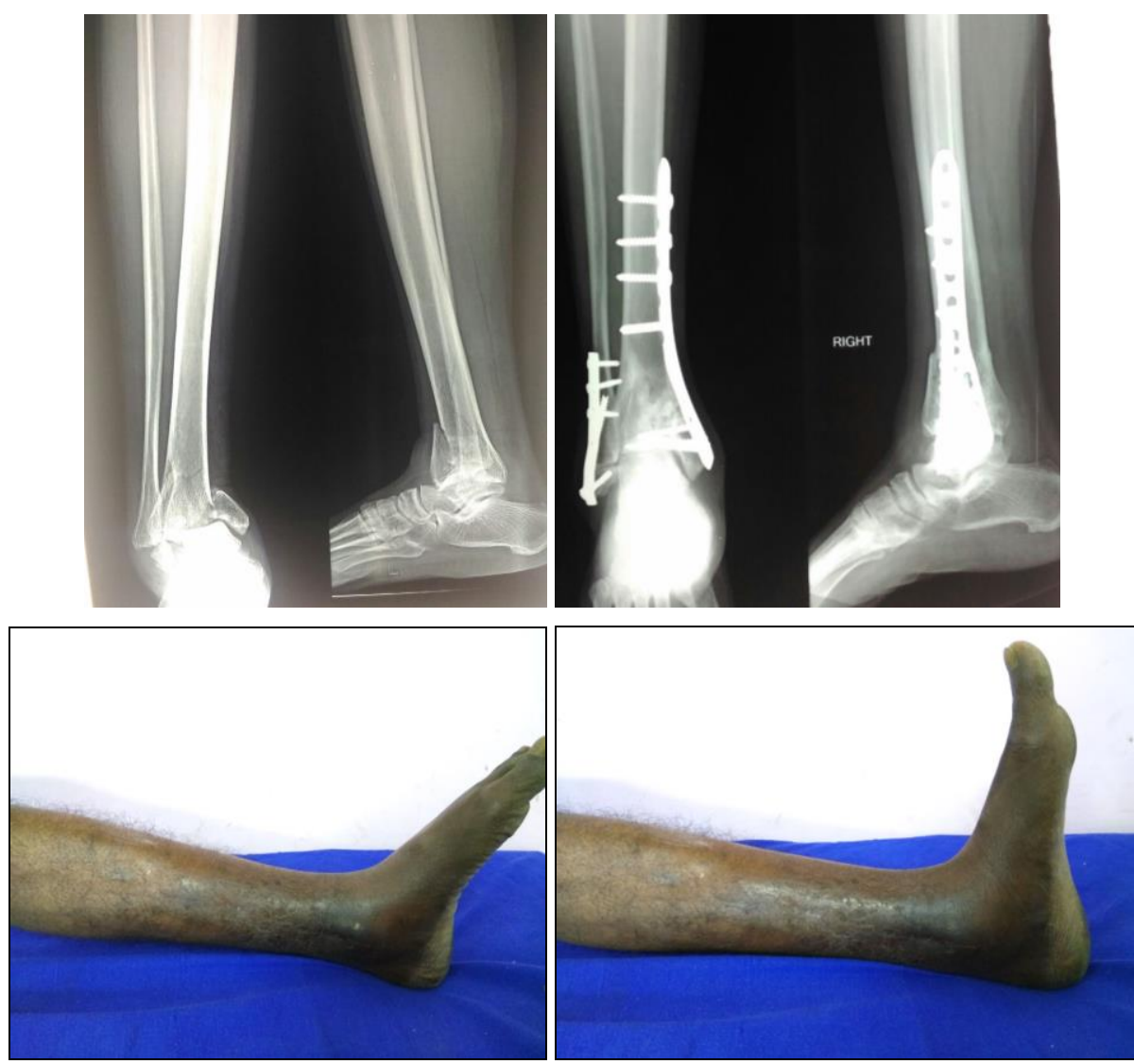

Case 1: Radiological union and range of movements.
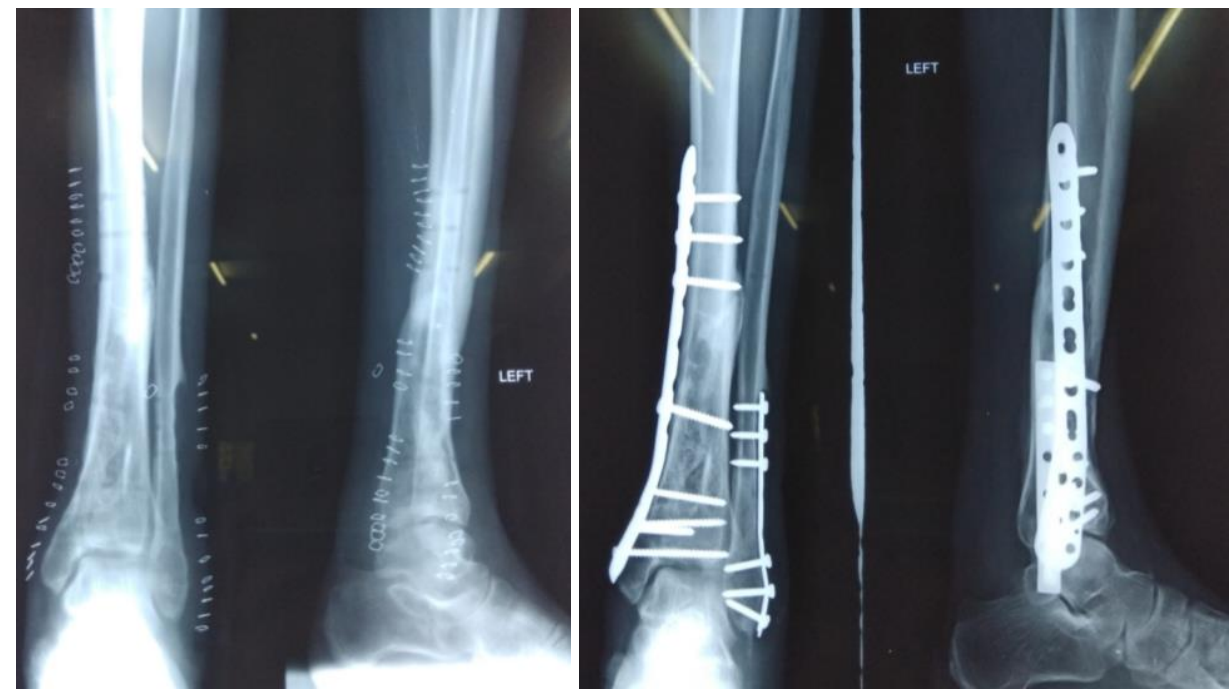

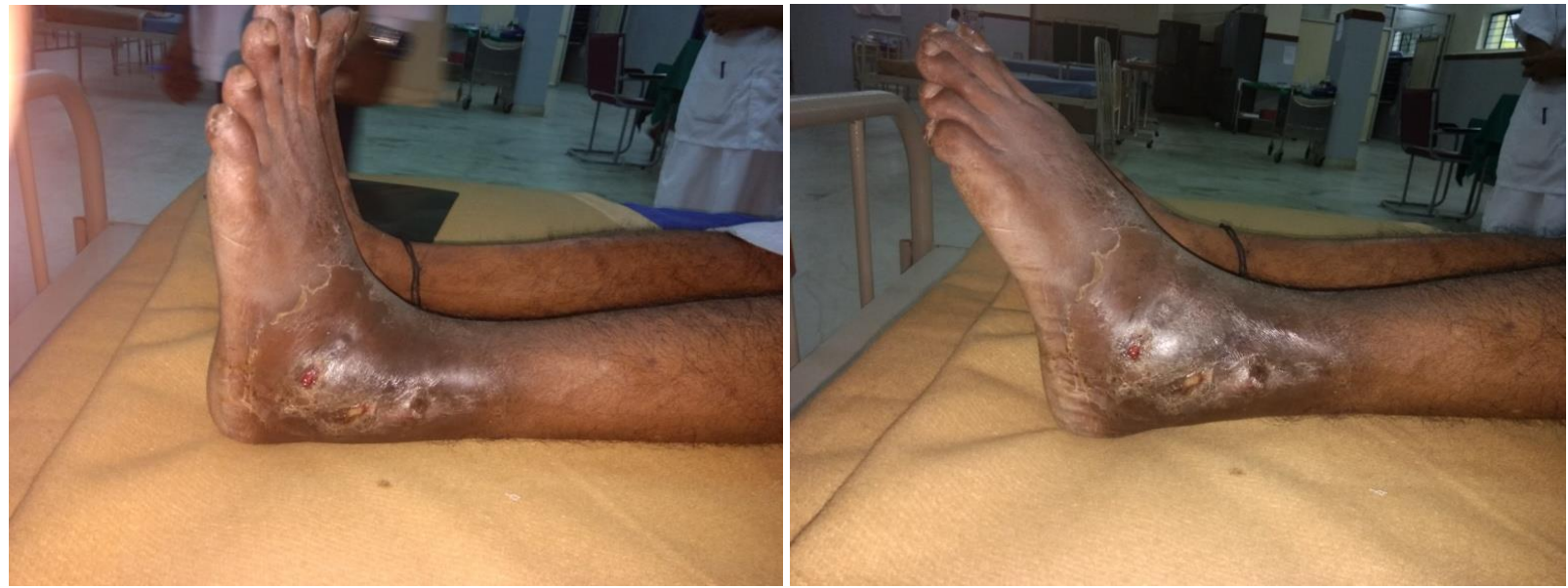

Case 2: Patient developed supeficial wound infection which was controlled with antibiotics till union.after union implant removal was done. pateint was a chonic smoker.
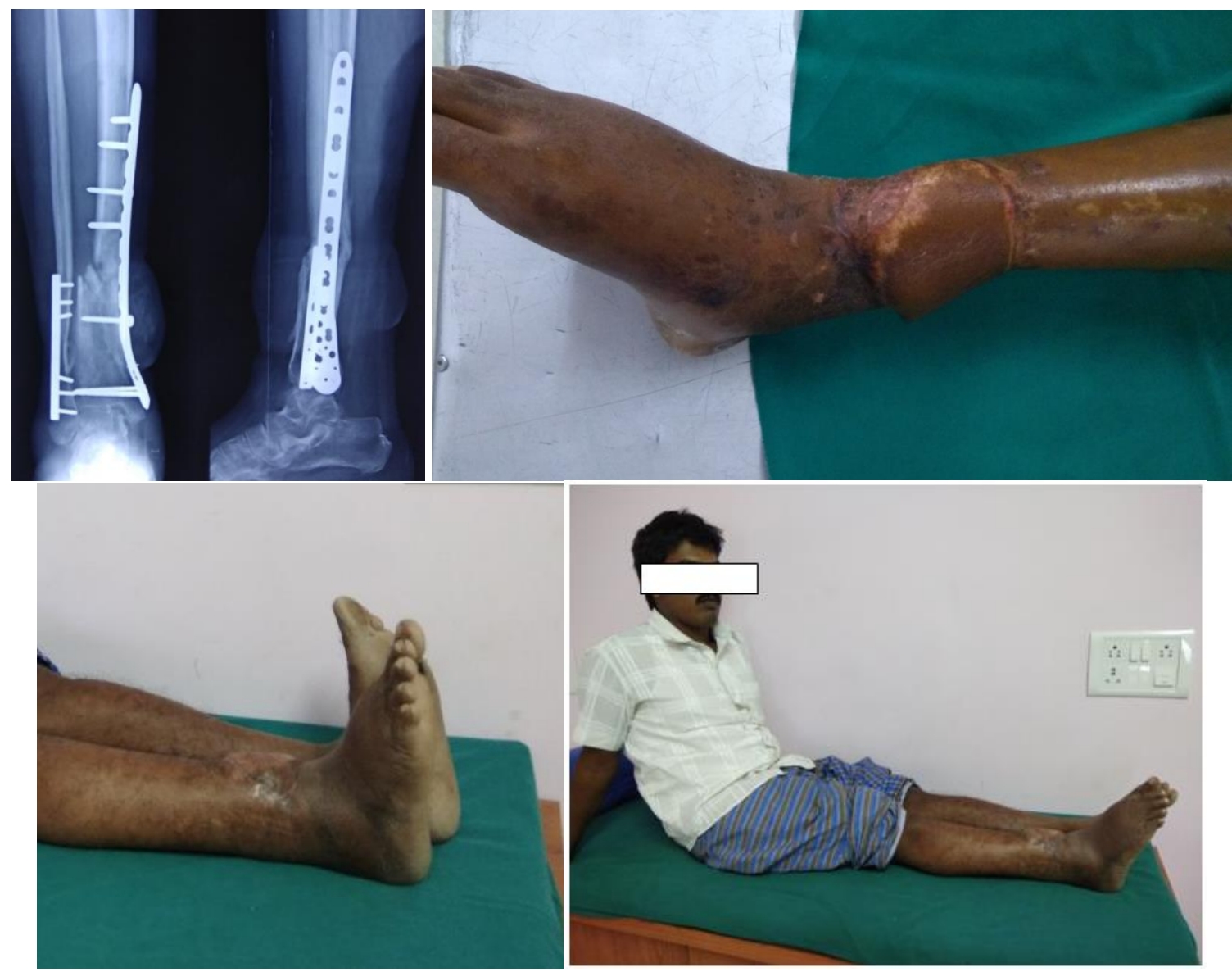

Case 3: Local flap cover was done for exposed plate on medial side. fracture united well.

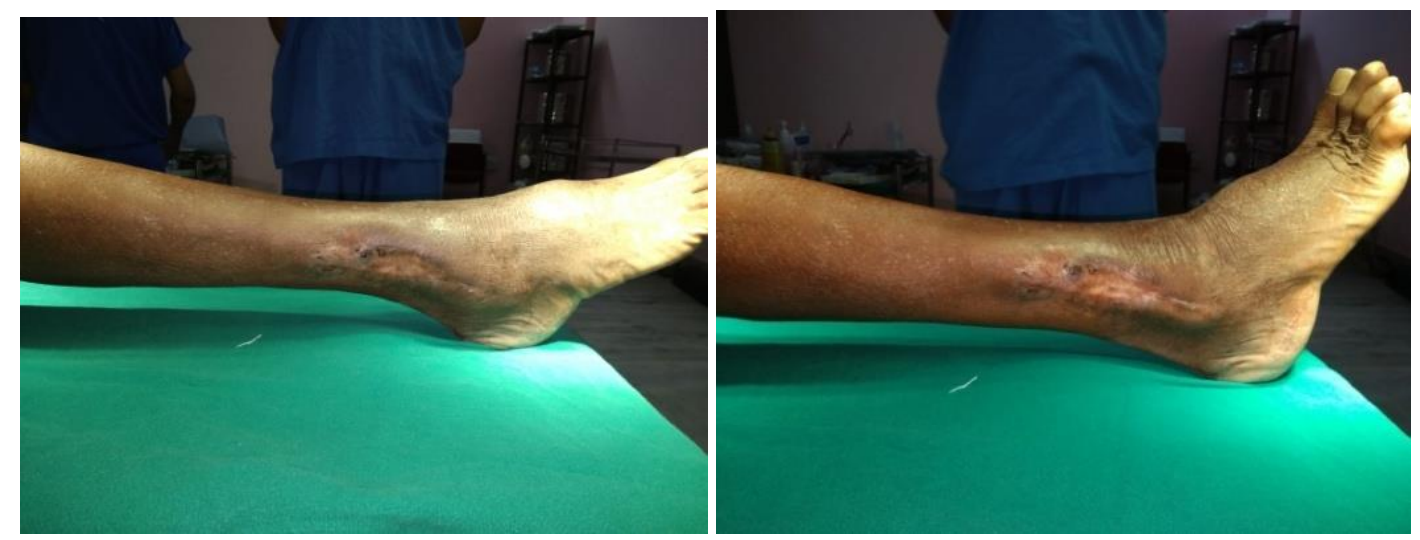




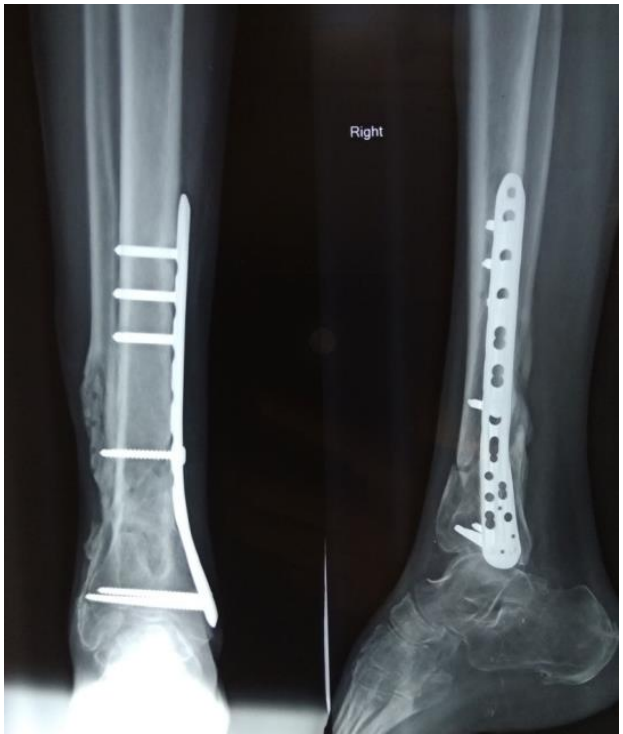

Case 4: Fibula osteomylitis. Implant removal and curratage was done after union. Wound healed well after fibula implant removal.

\section{References}

1. Bonar SK, Marsh JL. Tibial plafond fractures: changing principles of treatment. J Am Acad Orthop Surg. 1994; 2(6):297-305

2. Court-Brown CM. Tibia and Fibula. In: Court-Brown CM, Pennig D, eds. Oxford: Reed Education and Professional Publishing, Ltd., 1997:222-238.

3. Adler NE, Ostrove JM. Socioeconomic status and health: what we know and what we don't. Ann N Y Acad Sci. 1999; 896:3-15.

4. Backlund E, Sorlie PD, Johnson NJ. A comparison of the relationships of education and income with mortality: the National Longitudinal Mortality Study. Soc Sci Med. 1999; 49(10):1373-1384.

5. Feinstein JS. The relationship between socioeconomic status and health: a review of the literature. Milbank $Q$. 1993; 71(2):279-322.

6. Williams TM, Nepola JV, DeCoster TA, et al. Factors affecting outcome in tibial plafond fractures. Clin Orthop Relat Res. 2004; (423):93-98.

7. Borrelli J Jr, Ricci WM. Acute effects of cartilage impact. Clin Orthop Relat Res. 2004; (423):33-39.

8. Borrelli J Jr, Silva MJ, Zaegel MA, et al. Single highenergy impact load causes posttraumatic OA in young rabbits via a decrease in cellular metabolism. J Orthop Res. 2009; 27(3):347-352.

9. Borrelli J Jr, Tinsley K, Ricci WM, et al. Induction of chondrocyte apoptosis following impact load. J Orthop Trauma. 2003; 17(9):635-641.

10. McKinley TO, Rudert MJ, Tochigi Y, et al. Incongruitydependent changes of contact stress rates in human cadaveric ankles. J Orthop Trauma. 2006; 20(10):732738.

11. McKinley TO, Tochigi Y, Rudert MJ, et al. The effect of incongruity and instability on contact stress directional gradients in human cadaveric ankles. Osteoarthritis Cartilage. 2008; 16(11):1363-1369.

12. Vidović D, Matejčić A. Minimally-invasive plate osteosynthesis in distal tibial fractures: Results and complications. Epub Injury. 2015; 46(6):S96-9.

13. Duckworth AD, Jefferies JG, Type C. tibial pilon fractures: short- and long-term outcome following operative intervention. Bone Joint J. 2016; 98-B(8):110611.
14. Sönmez MM, Gülabi D. Minimal invasive fixation of distal tibial fractures does not result in rotational malalignment: A report of 24 cases with CT imaging. Ulus Travma Acil Cerrahi Derg. 2017; 23(2):144-149.

15. Chen DW, Li B, Aubeeluck A, Open reduction and internal fixation of posterior pilon fractures with buttress plate. Acta Ortop Bras. 2014; 22(1):48-53.

16. Bhat R, Wani MM, Rashid S, Akhter N. Minimally invasive percutaneous plate osteosynthesis for closed distal tibial fractures: a consecutive study based on 25 patients. Eur J Orthop Surg Traumatol. 2015; 25(3):563-8.

17. Hong J, Zeng R, Lin D. Orthopedics. Posteromedial anatomical plate for the treatment of distal tibial fractures with anterior soft tissue injury. 2011; 34(6):161.

18. Carbonell-Escobar R, Rubio-Suarez JC. Analysis of the variables affecting outcome in fractures of the tibial pilon treated by open reduction and internal fixation. J Clin Orthop Trauma. 2017; 8(4):332-338.

19. Howard JL, Agel J, Barei DP, et al. A prospective study evaluating incision placement and wound healing for tibial plafond fractures. J Orthop Trauma. 2008; 22(5):299-305; discussion 305-306.

20. Sirkin M, Sanders R. A staged protocol for soft tissue management in the treatment of complex pilon fractures. J Orthop Trauma. 2004; 18(8):S32-8.

21. Bacon S, Smith WR, Morgan SJ, et al. A retrospective analysis of comminuted intraarticular fractures of the tibial plafond: Open reduction and internal fixation versus external Ilizarov fixation. Injury. 2008; 39(2):196202.

22. Ruedi TP, Allgower M. The operative treatment of intraarticular fractures of the lower end of the tibia. Clin Orthop Relat Res. 1979; (138):105-110.

23. Leonard M, Magill P, Khayyat G. Minimally-invasive treatment of high velocity intraarticular fractures of the distal tibia. Int Orthop. 2008; 33(4):1149-1153

24. Patterson MJ, Cole JD. Two-staged delayed open reduction and internal fixation of severe pilon fractures. $\mathrm{J}$ Orthop Trauma. 1999; 13(2):85-91

25. Bourne RB, Rorabeck $\mathrm{CH}$, Macnab J. Intra-articular fractures of the distal tibia: the pilon fracture. J Trauma. 1983; 23(7):591-596.

26. Aggarwal AK, Nagi ON. Hybrid external fixation in 
periarticular tibial fractures. Good final outcome in 56 patients. Acta Orthop Belg. 2006; 72(4):434-440.

27. Demiralp B, Atesalp AS, Bozkurt M, et al. Spiral and oblique fractures of distal onethird of tibia-fibula: treatment results with circular external fixator. Ann Acad Med Singapore. 2007; 36(4):267-271.

28. Borg T, Larsson S, Lindsjo U. Percutaneous plating of distal tibial fractures. Preliminary results in 21 patients. Injury. 2004; 35(6):608-614.

29. Collinge C, Kuper M, Larson K, et al. Minimally invasive plating of high-energy metaphyseal distal tibia fractures. J Orthop Trauma. 2007; 21(6):355-361.

30. Konrath G, Moed BR, Watson JT, et al. Intramedullary nailing of unstable diaphyseal fractures of the tibia with distal intraarticular involvement. J Orthop Trauma. Murphy CP, D'Ambrosia R, Dabezies EJ. The small pin circular fixator for distal tibial pilon fractures with soft tissue compromise. Orthopedics. 1991; 14(3):283-290.

31. Bourne RB, Rorabeck CH, Macnab J. Intra-articular fractures of the distal tibia: the pilon fracture. J Trauma. 1983; 23(7):591-596.

32. Babis GC, Vayanos ED, Papaioannou N, et al. Results of surgical treatment of tibial plafond fractures. Clin Orthop Relat Res. 1997; (341):99-105.

33. Kellam JF, Waddell JP. Fractures of the distal tibial metaphysis with intra-articular extension-the distal tibial explosion fracture. J Trauma. 1979; 19(8):593-601.

34. Thomas TP, Anderson DD, Mosqueda TV, et al. Objective CT-based metrics of articular fracture severity to assess risk for posttraumatic osteoarthritis. J Orthop Trauma. 2010; 24(12):764-769. 